\title{
Assessment of Left Atrial Functions in Patients with Prediabetes
}

\author{
Oyku Gulmez $^{1^{*}}$, Hulya Parıldar ${ }^{2}$, Ozlem Cigerli, and Nilgün Guvener Demirag ${ }^{3}$
}

${ }^{1}$ Department of Cardiology, Baskent University Istanbul Medical and Research Center, Istanbul, Turkey

${ }^{2}$ Department of Family Medicine, Baskent University Istanbul Medical and Research Center, Istanbul, Turkey

${ }^{3}$ Department of Endocrinology and Metabolism, Baskent University Istanbul Medical and Research Center, Istanbul, Turkey

"Corresponding author: Oyku Gulmez, Department of Cardiology, Baskent University Istanbul Medical and Research Center, Oymacı sok, no: 7; 34662 Altunizade, Istanbul, Turkey, Tel: +90 5352496139; Fax: +902616519858; E-mail: gulmezoyku@yahoo.com

Rec date: August 31, 2017; Acc date: September 6, 2017; Pub date: September 13, 2017

Copyright: $\odot 2017$ Gulmez O. This is an open-access article distributed under the terms of the Creative Commons Attribution License, which permits unrestricted use, distribution, and reproduction in any medium, provided the original author and source are credited.

\begin{abstract}
Background: LA volumes and functions are reported to be independent predictors of cardiovascular events in general and diabetic population. The aim of this is to evaluate the effects of prediabetes on LA volumes and functions and parameters that effect LA volumes and functions in patients with prediabetes.

Methods: 114 patients (83 female, mean age $48.6 \pm 7.4$ years) with prediabetes and 70 controls (46 female, mean age $46.5 \pm 9.4$ years) were included in the study. LA volumes (indexed maximal LA volume- $V_{\text {max }}$, pre-atrial contraction volume- $\mathrm{V}_{\text {olp }}$, minimal $L A$ volume- $\mathrm{V}_{\min }$ ) and functions (passive emptying volume-fraction (PEV-PEF), active emptying volume-fraction (AEV-AEF), total emptying volume-fraction (TEV-TEF) were evaluated with 2dimentional echocardiography and indexed to body surface area.
\end{abstract}

Results: LA diameter, indexed $\mathrm{V}_{\max }, \mathrm{V}_{\text {olp }}, \mathrm{V}_{\min }, A E \mathrm{~V}$, and TEV were found to be significantly higher in preDM group compared with control group $(P<0.05)$. There were significant positive correlation between all three $L A$ volumes and body mass index (BMI), triglyceride, $\mathrm{HbA} 1 \mathrm{c}$, fasting glucose, high sensitive C-reactive protein, mitral $\mathrm{A}$ wave and deceleration time. Additionally, there were positive correlation between AEV, TEV and BMI. Multivariate analysis showed that the BMI had statistically significant effect on LA diameter, indexed $V_{\text {max }}$, indexed $V_{\text {olp }}$, indexed PEV and indexed TEV whereas prediabetes had statistically significant effect on indexed $V_{\text {max }}$, indexed $V_{\text {olp }}$ and indexed $V_{\text {min }}$. HT had only statistically significant effect on indexed $V_{\max }$.

Conclusion: BMI and prediabetes have significant effect on LA volumes, but BMI is the only factor that has significant effect on LA functions. On the basis of these findings, we speculate that impairment of LA volumes and functions may be present before overt DM begins and this finding was mainly due to prediabetes and BMI.

Keywords: Left atrial volume; Left atrial function; Prediabetes; Transthoracic echocardiography

\section{Introduction}

Prediabetes (preDM) can be defined as an intermediate stage between normal glucose tolerance (NGT) and overt type 2 diabetes mellitus (DM) [1]. It has been well described that type $2 \mathrm{DM}$ is associated with a marked increase in cardiovascular events (CVE). Recently, it has been shown that individuals with prediabetes are also at high risk to experience adverse CVE later in life [1,2]. Moreover, preDM is associated with left ventricular (LV) structure abnormalities and diastolic dysfunction even in the presence of normal systolic function in patients without coronary artery disease [3-5]. Assessment of left atrium (LA) functions is a groving interest as LA serves as a reservoir during ventricular systole, as a conduit during early diastole, and as an active contractile chamber that augment left ventricular filling in late diastole [6,7]. Recently published trial by Kadappu et al demonstrated that LA dilatation and dysfunction may be a coexistent diastolic dysfunction marker in patients with DM [8]. Additionally, most investigators reported LA volumes and functions are independent predictors of CVE in general and diabetic population

Gen Med (Los Angeles), an open access journal

ISSN:2327-5146
[9-17]. However, there is limited data about the effects of preDM on LA volumes and functions.

In this study, we examined 1 . The effects of preDM on LA volumes and functions and 2. The parameters that effect LA volumes and functions in patients with preDM.

\section{Methods and Materials}

\section{Study population}

One hundred fourteen patients (83 female, mean age $48.6 \pm 7.4$ years) with preDM who were requited from endocrinology department (impaired fasting glucose-IFG defined as elevated fasting plasma glucose concentration, 100 and $126 \mathrm{mg} / \mathrm{dL}$ and impaired glucose tolerance test-IGT defined as elevated 2-hour plasma glucose concentration, $140-200 \mathrm{mg} / \mathrm{dL}$ according to American Diabetes Assocation (ADA) 2013 criteria) and 70 age-matched healthy volunteers (46 female, mean age $46.5 \pm 9.4$ years) who were requited from cardiology department were included in the study [18]. A detailed medical history, physical examination and 12-lead electrocardiography were obtained from the study population. All subjects underwent treadmill exercise test according to Bruce protocol or myocardial perfusion scintigrapyh to rule out latent ischemia. 
Patients with evidence of ischemia, arrhythmia on electrocardiogram LV dysfunction with an ejection fraction of $<50 \%$, significant valvular diseases, history of coronary artery disease, suspicion of secondary hypertension, thyroid disorders, pulmonary diseases, and renal failure (defined as decreased glomerular filtration rate of $<60 \mathrm{~mL} / \mathrm{min} / 1.73 \mathrm{~m}^{2}$ for at least 3 months), electrolyte imbalance, technically insufficient echocardiographic and electrocardiographic data were excluded. The study protocol was approved by our local ethical committee. All participants gave informed consent before participation into the study.

\section{Transthoracic echocardiography}

Transthoracic echocardiographic examinations were performed using commercially available cardiac ultrasound scanner equipped with a multifrequency transducer and Doppler imaging program (Acuson Sequoia 512 System with 2.5 to $4.0 \mathrm{MHz}$ transducer, Siemens Mountain View, California, USA) in the left lateral position according to the criteria of the American Society of Echocardiography [19]. During echocardiography, one-lead ECG recording was recorded continuously.

Left ventricular end-diastolic and end-systolic volumes were determined from the apical 4- and 2- chamber views, and stroke volume and ejection fraction (EF) were measured using the modified Simpson equation [19]. The LV mass was calculated with the Devereux Formula as $\operatorname{LVM}(\mathrm{g})=1.04\left[(\mathrm{LVID}+\mathrm{PWT}+\mathrm{IVST})^{3}-\mathrm{LVID}^{3}\right]-14$ (LVID: LV internal dimension; PWT: posterior wall thickness; IVST: interventricular septum thickness) and indexed to the body surface area (BSA) (dividing LVM by body surface area). The peak early diastolic (E) velocity, and atrial contraction (A) velocity and $\mathrm{E}$ wave deceleration time (DT) were measured from the transmitral pulsed wave Doppler spectrum and E/A ratio was calculated. The pulsed wave tissue Doppler imaging (TDI) was performed in apical four-chamber window with a sample volume of $5 \mathrm{~mm}$. The monitor sweep speed was set at $100 \mathrm{~mm} / \mathrm{sec}$ to optimize the spectral display of myocardial velocities and all Doppler spectral velocities were averaged over three consecutive beats. The average pulsed wave TDI derived early (E') diastolic myocardial velocity was obtained from the lateral and septal sides of mitral annulus. Then, E/E' ratio was calculated to provide an estimation of LV filling pressures. The TDI derived late diastolic wave (A') was obtained from the mitral lateral annulus [20].

The LA diameter was measured from the parasternal long axis with M-mode echocardiography. Left atrial volumes were traced and calculated by means of a modified Simpson method from apical 4- and 2- chamber views according to the guidelines of the American College of Cardiology [19]. LA volumes were measured as: 1) maximal LA volume $\left(\mathrm{V}_{\max }\right)$ : just before mitral valve opening, at end-sytole 2$)$ preatrial contraction volume $\left(\mathrm{V}_{\mathrm{olp}}\right)$ : at the onset of the $\mathrm{P}$-wave on electrocardiography; and 3) minimal LA volume $\left(\mathrm{V}_{\min }\right)$ : at mitral valve closure, at end-diastole. All LA volumes were indexed to BSA in all patients. From these, the following measurements were calculated to estimate LA functions:

1. LA passive emptying volume $(\mathrm{PEV})=\mathrm{V}_{\max }-\mathrm{V}_{\text {olp }}$;

2. LA passive emptying fraction $(\mathrm{PEF})=\mathrm{PEV} / \mathrm{V}_{\max } \times 100$;

3. LA active emptying volume $(\mathrm{AEV})=\mathrm{V}_{\mathrm{olp}}-\mathrm{V}_{\text {min }}$;

4. LA active emptying fraction $(\mathrm{AEF})=\mathrm{AEV} / \mathrm{V}_{\mathrm{olp}} \times 100$;

5. LA total emptying volume $(\mathrm{TEV})=\mathrm{V}_{\max }-\mathrm{V}_{\min }$.
6. LA total emptying fraction $(\mathrm{TEF})=\mathrm{TEV} / \mathrm{V}_{\max } \times 100$. Left atrial volumes were indexed to body surface area (BSA) in all patients [21].

\section{Statistical analysis}

The statistical analyses were performed with the MedCalc Statistical Software version 12.7.7 (MedCal Software bvbv, Ostend, Belgium; 2013). All continuous variables were expressed as mean \pm standard deviation, and categorical variables were defined as frequency and percentages. All continuous variables were checked with KolmogorovSmirnov normality test to show their distributions. Continuous variables with normal distributions were compared using the unpaired Student $\mathrm{t}$ test. For categorical variables, the chi-square test was used. Pearson and Spearman correlation analysis was used to evaluate correlations between LA volumes and functions and various laboratory parameters, and 2D echocardiographic diastolic parameters. Multivariate evaluations were performed by using Lineer Regression Analysis. The confounders that were found to be statistically significant impact on the dependent variable upon univariate analysis were described as the independent variables in multivariate linear regression analysis model. The $\mathrm{P}$ values $<0.05$ was considered significant.

Sample size justification: According to the article 'Atrial conduction times and left atrial mechanical functions and their relation with diastolic function in prediabetic patients" study (ref no 22) $\mathrm{V}_{\min }$ value at prediabets was $9.6 \pm 6.1 \mathrm{~mL}$ and for the control group $13.1 \pm 4.3 \mathrm{~mL}$. The mean difference was assumed as 3.5 and the standard deviation of the prediabetes group was 6.1 and of the control group 4.3. With the assumption of $5 \%$ of type I error (a) and $90 \%$ of power (1-b), 49 patients for each group was calculated as the sample size. With a $25 \%$ drop-out rate, minimum 62 patients (in total 124) patients should be enrolled to the study.

\section{Results}

Patient characteristics analyzed according to groups are shown in Table 1. A total of 184 patients with mean age $47.8 \pm 8.3$ years and 129 $(70.1 \%)$ female were included in this study. There were no significant differences between both groups in age and sex distribution ( $\mathrm{p}>0.05)$. Hypertension was present in 49 (43\%) patients in preDM group, and 6 $(8.6 \%)$ individuals in control group $(\mathrm{p}<0.05) .27(14.7 \%)$ patients in preDM group were taking oral antidiabetics. In preDM group, patients were taking more frequent medications of acetylsalicylic acid, angiotensin-converting enzyme inhibitors, beta-blockers and statins than control group. Body mass index (BMI), triglyceride, high sensitive C-reactive protein (hsCRP), uric asid, fasting glucose, HbAlc were significantly higher in preDM group compared with control group $(\mathrm{p}<0.05)$. There were no significant difference regarding total cholesterol, LDL, HDL levels ( $p>0.05$ ).

Both groups were compared to each other with respect to $2 \mathrm{D}$ echocardiographic parameters. Diastolic dysfunction was present in 33 (28.9\%) patients in preDM group, and $12(17.1 \%)$ individual in control group $(\mathrm{p}=0.08)$. There were no significant differences between the groups regarding $\mathrm{EF}$ and mitral $\mathrm{E}$ wave. However, LV mass, mitral A and $A^{\prime}$ waves, E/E' ratio, deceleration time were significantly higher and mitral E' wave was significantly lower in preDM group compared with control group $(\mathrm{p}<0.05)$ (Table 2$)$. 
Citation: Gulmez O, Parildar H, Cigerli O, Demirag NG (2017) Assessment of Left Atrial Functions in Patients with Prediabetes . Gen Med (Los Angeles) 5: 296. doi:10.4172/2327-5146.1000296

Page 3 of 7

\begin{tabular}{|c|c|c|c|}
\hline Characteristics & PreDM group n=114 & Control Group n=70 & $\mathbf{P}$ \\
\hline Age, year & $48.6 \pm 7.4$ & $46.5 \pm 9.4$ & 0.083 \\
\hline Female, $n(\%)$ & $83(72.8)$ & $46(65.7)$ & 0.324 \\
\hline BMI $\left(\mathrm{kg} / \mathrm{m}^{2}\right)$ & $25.2 \pm 5.2$ & $22.3 \pm 1.9$ & $<0.001$ \\
\hline Tobacco use, n (\%) & $21(18.4)$ & $9(12.9)$ & 0.412 \\
\hline Hypertension, n (\%) & $49(43)$ & $6(8.6)$ & $<0.001$ \\
\hline Hyperlipidemia, n (\%) & $68(59.6)$ & $11(15.7)$ & $<0.001$ \\
\hline \multicolumn{4}{|l|}{ Medications, n (\%) } \\
\hline ACEI & $40(35.1)$ & $5(7.1)$ & $<0.001$ \\
\hline Betablockers & $15(13.2)$ & $1(1.4)$ & 0.006 \\
\hline Statins & $49(43)$ & $5(7.1)$ & $<0.001$ \\
\hline ASA & $23(20.2)$ & $3(4.3)$ & 0.002 \\
\hline OAD & $27(14.7)$ & - & - \\
\hline Fasting glucose (mg/dL) & $105.6 \pm 8.8$ & $92.7 \pm 6.9$ & $<0.001$ \\
\hline $\mathrm{HbA} 1 \mathrm{C}(\%)$ & $5.7 \pm 0.6$ & $4.8 \pm 0.5$ & $<0.001$ \\
\hline Total cholesterol (mg/dL) & $217.5 \pm 33.9$ & $207.7 \pm 39.6$ & 0.076 \\
\hline $\mathrm{HDL}(\mathrm{mg} / \mathrm{dL})$ & $51.4 \pm 15.2$ & $48.8 \pm 12.8$ & 0.55 \\
\hline LDL (mg/dL) & $137.6 \pm 32.8$ & $128.2 \pm 36.7$ & 0.72 \\
\hline TG (mg/dL) & $159.5 \pm 75.4$ & $133.2 \pm 79.2$ & 0.025 \\
\hline hsCRP (mg/L) & $3.4 \pm 2.1$ & $1.8 \pm 1.1$ & $<0.001$ \\
\hline Uric acid (mg/dL) & $5.6 \pm 1.7$ & $4.6 \pm 1.0$ & $<0.001$ \\
\hline
\end{tabular}

BMI: Body Mass Index, ACEl: Angiotensin Converting Enzyme Inhibitors, ASA: Acetylsalisilic Acid, OAD: Oral Antidiabetics, HbA1C: Glycosylated Hemoglobin, HDL: High Density Lipoprotein, LDL: low density Lipoprotein, TG: Triglyceride, hSCRP: High Sensitive C-reactive Protein

Table 1: Demographic characteristics and laboratory parameters of the groups.

\begin{tabular}{|c|c|c|c|}
\hline Parameters & PreDM Group n=114 & Control Group n=70 & $\mathbf{P}$ \\
\hline Ejection fraction (\%) & $62.7 \pm 5.8$ & $62.1 \pm 5.0$ & 0.526 \\
\hline Left ventricular mass $\left(\mathrm{g} / \mathrm{m}^{2}\right)$ & $110.1 \pm 11.8$ & $106.0 \pm 10.3$ & 0.015 \\
\hline Mitral E (cm/s) & $81.5 \pm 14.3$ & $81.8 \pm 15.8$ & 0.887 \\
\hline Mitral A (cm/s) & $74.6 \pm 17.3$ & $66.9 \pm 14.7$ & 0.002 \\
\hline E/A ratio $(\mathrm{cm} / \mathrm{s})$ & $1.1 \pm 0.2$ & $1.2 \pm 0.3$ & 0.002 \\
\hline Deceleration time (s) & $210.7 \pm 24.5$ & $198.6 \pm 23.3$ & 0.001 \\
\hline Mitral lateral E' (cm/s) & $16.6 \pm 3.9$ & $18.2 \pm 3.7$ & 0.008 \\
\hline Mitral lateral $A^{\prime}(\mathrm{cm} / \mathrm{s})$ & $14.8 \pm 4.0$ & $13.1 \pm 2.6$ & 0.002 \\
\hline $\mathrm{E} / \mathrm{E}^{\prime}$ ratio $(\mathrm{cm} / \mathrm{s})$ & $5.1 \pm 1.4$ & $4.4 \pm 0.9$ & 0.001 \\
\hline Diastolic dysfunction, n (\%) & $33(28.9)$ & $12(17.1)$ & 0.079 \\
\hline
\end{tabular}

Table 2: Echocardiographic parameters of the groups. 
Citation: Gulmez O, Parildar H, Cigerli O, Demirag NG (2017) Assessment of Left Atrial Functions in Patients with Prediabetes . Gen Med (Los Angeles) 5: 296. doi:10.4172/2327-5146.1000296

Page 4 of 7

Table 3 shows the $2 \mathrm{D}$ echocardiographic evaluation of LA volumes and functions. LA diameter, indexed $V_{\max }, V_{\text {olp }}, V_{\text {min }}$ were significantly higher in preDM group compared with control group $(\mathrm{p}<0.05)$. Regarding parameters reflecting LA functions, indexed AEV,
TEV were significantly higher in preDM group compared with control group, whereas there were no significant difference between the groups regarding indexed PEV, AEF, PEF and TEF ( $\mathrm{p}>0.05)$.

\begin{tabular}{|l|l|l|l|}
\hline Parameters & PreDM Group $\mathbf{n = 1 1 4}$ & Control Group $\mathbf{n = 7 0}$ & $\mathbf{P}$ \\
\hline LA diameter $(\mathrm{mm})$ & $37.3 \pm 5.9$ & $33.8 \pm 4.9$ & $<0.001$ \\
\hline Indexed $\mathrm{Vmax}\left(\mathrm{mL} / \mathrm{m}^{2}\right)$ & $24.0 \pm 5.3$ & $19.8 \pm 4.8$ & $<0.001$ \\
\hline Indexed Volp $\left(\mathrm{mL} / \mathrm{m}^{2}\right)$ & $15.5 \pm 4.7$ & $12.4 \pm 4.0$ & $<0.001$ \\
\hline Indexed $\mathrm{Vmin}\left(\mathrm{mL} / \mathrm{m}^{2}\right)$ & $9.4 \pm 3.5$ & $7.4 \pm 2.7$ & $<0.001$ \\
\hline Indexed PEV $\left(\mathrm{mL} / \mathrm{m}^{2}\right)$ & $8.4 \pm 3.6$ & $7.4 \pm 3.7$ & 0.064 \\
\hline Indexed AEV $\left(\mathrm{mL} / \mathrm{m}^{2}\right)$ & $6.0 \pm 2.9$ & $4.9 \pm 2.6$ & 0.012 \\
\hline Indexed TEV $\left(\mathrm{mL} / \mathrm{m}^{2}\right)$ & $14.5 \pm 3.7$ & $12.4 \pm 3.8$ & $<0.001$ \\
\hline LA Passive emptying fraction (\%) & $35.1 \pm 12.4$ & $36.9 \pm 14.5$ & 0.367 \\
\hline LA Active emptying fraction (\%) & $38.4 \pm 12.7$ & $39.5 \pm 13.5$ & 0.583 \\
\hline LA Total emptying fraction (\%) & $60.7 \pm 9.0$ & $62.4 \pm 10.7$ & 0.238 \\
\hline LA: Left Atrium, PEV: Passive Emptying Volume, AEV: Active Emptying Volume, TEV: Total Emptying Volume & \\
\hline
\end{tabular}

Table 3: The echocardiographic parameters for the LA volumes and functions of the groups.

There were weak but significant correlation between indexed $\mathrm{V}_{\max }$, $\mathrm{V}_{\text {olp }}, \mathrm{V}_{\min }$ and BMI, triglycerides, HbAlc, fasting glucose, hsCRP, mitral A wave and deceleration time. There were also weak, positive correlation between indexed $\mathrm{V}_{\text {olp }}$, indexed $\mathrm{V}$ min and $\mathrm{E} / \mathrm{E}^{\prime}$ ratio. Additionally, there were weak positive correlation between indexed $\mathrm{AEV}$, indexed TEV and BMI (Table 4). The univariate analysis showed that preDM, HT, BMI, and hs-CRP levels had statistically significant impact on the LA diameter, indexed $\mathrm{V}_{\max }$, indexed $\mathrm{V}_{\text {olp }}$, indexed $\mathrm{V}_{\text {min }}$, and indexed TEV. According to the multivariate analysis when adjusted with other confounders BMI had statistically significant effect on LA diameter, indexed $\mathrm{V}_{\text {max }}$, indexed $\mathrm{V}_{\text {olp }}$, indexed PEV and indexed TEV, whereas prediabetes has statistically significant effect on indexed $\mathrm{V}_{\text {max }}$, indexed $\mathrm{V}_{\text {olp }}$ and indexed $\mathrm{V}_{\min }$. HT had only statistically significant effect on indexed $\mathrm{V}_{\max }$ (Table 5).

\begin{tabular}{|c|c|c|c|c|c|c|}
\hline \multicolumn{2}{|c|}{ Parametes } & $\begin{array}{l}\text { Indexed } \\
\mathrm{V}_{\max } \\
\left(\mathrm{ml} / \mathrm{m}^{2}\right)\end{array}$ & $\begin{array}{l}\text { Indexed } V_{\text {olp }} \\
\left(\mathrm{ml} / \mathrm{m}^{2}\right)\end{array}$ & $\begin{array}{l}\text { Indexed } V_{\text {min }} \\
\left(\mathrm{ml} / \mathrm{m}^{2}\right)\end{array}$ & $\begin{array}{l}\text { Indexed AEV } \\
\left(\mathrm{ml} / \mathrm{m}^{2}\right)\end{array}$ & $\begin{array}{l}\text { Indexed TEV } \\
\left(\mathrm{ml} / \mathrm{m}^{2}\right)\end{array}$ \\
\hline \multirow{2}{*}{$\begin{array}{l}\text { Glucose } \\
\text { (mg/dL) }\end{array}$} & $r$ & 0.19 & 0.183 & 0.216 & 0.043 & 0.079 \\
\hline & $\mathrm{P}$ & 0.01 & 0.013 & 0.003 & 0.56 & 0.289 \\
\hline \multirow{2}{*}{$\begin{array}{l}\mathrm{HbA1C} \\
(\%)\end{array}$} & $r$ & 0.249 & 0.244 & 0.215 & 0.143 & 0.163 \\
\hline & $p$ & 0.001 & 0.001 & 0.003 & 0.053 & 0.027 \\
\hline \multirow{2}{*}{$\begin{array}{l}\text { BMI } \\
\left(\mathrm{kg} / \mathrm{m}^{2}\right)\end{array}$} & $r$ & 0.385 & 0.267 & 0.22 & 0.175 & 0.349 \\
\hline & $p$ & $<0.001$ & $<0.001$ & 0.003 & 0.017 & $<0.001$ \\
\hline \multirow{2}{*}{$\begin{array}{l}\text { TG } \\
(\mathrm{mg} / \mathrm{dL})\end{array}$} & $r$ & 0.181 & 0.166 & 0.202 & 0.033 & 0.078 \\
\hline & $\mathrm{p}$ & 0.014 & 0.024 & 0.006 & 0.655 & 0.294 \\
\hline \multirow{2}{*}{$\begin{array}{l}\text { hsCRP } \\
(\mathrm{mg} / \mathrm{L})\end{array}$} & $r$ & 0.252 & 0.179 & 0.211 & 0.043 & 0.171 \\
\hline & $p$ & 0.001 & 0.015 & 0.004 & 0.562 & 0.02 \\
\hline \multirow{2}{*}{$\begin{array}{l}\text { Uric acid } \\
\text { (mg/dL) }\end{array}$} & $r$ & 0.154 & 0.061 & 0.108 & -0.027 & 0.122 \\
\hline & $\mathrm{p}$ & 0.037 & 0.411 & 0.146 & 0.714 & 0.099 \\
\hline
\end{tabular}


Citation: Gulmez O, Parildar H, Cigerli O, Demirag NG (2017) Assessment of Left Atrial Functions in Patients with Prediabetes . Gen Med (Los

Page 5 of 7

\begin{tabular}{|l|l|l|l|l|l|l|}
\hline \multirow{2}{*}{$\begin{array}{l}\text { Mitral A } \\
(\mathrm{cm} / \mathrm{s})\end{array}$} & $\mathrm{r}$ & 0.233 & 0.199 & 0.196 & 0.092 & 0.156 \\
\cline { 2 - 7 } & $\mathrm{p}$ & 0.001 & 0.007 & 0.008 & 0.213 & 0.034 \\
\hline $\begin{array}{l}\text { Mitral E' } \\
(\mathrm{cm} / \mathrm{s})\end{array}$ & $\mathrm{r}$ & -0.94 & -0.046 & -0.095 & 0.036 & -0.05 \\
\cline { 2 - 7 } & $\mathrm{p}$ & 0.202 & 0.532 & 0.201 & 0.628 & 0.5 \\
\hline $\begin{array}{l}\text { Mitral A' } \\
(\mathrm{cm} / \mathrm{s})\end{array}$ & $\mathrm{r}$ & 0.198 & 0.129 & 0.103 & 0.089 & 0.188 \\
\cline { 2 - 7 } & $\mathrm{p}$ & 0.007 & 0.08 & 0.164 & 0.229 & 0.01 \\
\hline $\begin{array}{l}\text { E/E' ratio } \\
(\mathrm{cm} / \mathrm{s})\end{array}$ & $\mathrm{r}$ & 0.144 & 0.167 & 0.22 & 0.013 & 0.11 \\
\cline { 2 - 7 } & $\mathrm{p}$ & 0.051 & 0.024 & 0.003 & 0.859 & -0.879 \\
\hline $\begin{array}{l}\text { E/A ratio } \\
(\mathrm{cm} / \mathrm{s})\end{array}$ & $\mathrm{r}$ & 0.233 & -0.139 & -0.144 & -0.56 & 0.188 \\
\cline { 2 - 6 } & $\mathrm{p}$ & 0.002 & 0.06 & 0.05 & 0.451 \\
\hline $\begin{array}{l}\text { BMI: Body Mass Index } \\
\text { Emptying Volume. }\end{array}$ & \multicolumn{2}{|l|}{ TG: Triglycerides, hs-CRP: High Sensitive C-reactive Protein,PEV: Passive Emptying Volume, AEV: Active Emptying Volume, TEV: Total } \\
\hline
\end{tabular}

Table 4: Correlation analysis of left atrial volumes and functions with 2D echocardiographic parameters and laboratory findings.

\begin{tabular}{|c|c|c|c|c|c|c|c|c|c|c|c|c|c|c|}
\hline \multirow[b]{2}{*}{ Parameters } & \multicolumn{7}{|c|}{ Univariate Analysis } & \multicolumn{7}{|c|}{ Multivariate Analysis } \\
\hline & preDM & HT & HL & Age & BMI & hsCRP & $\begin{array}{l}\text { Uric } \\
\text { Acid }\end{array}$ & preDM & HT & HL & Age & BMI & hsCRP & $\begin{array}{l}\text { Uric } \\
\text { Acid }\end{array}$ \\
\hline LA diameter (mm) & 0.004 & $<0.001$ & 0.373 & 0.089 & $<0.001$ & 0.032 & 0.177 & 0.189 & 0.061 & - & - & $<0.001$ & 0.484 & - \\
\hline Indexed $\mathrm{V}_{\max }\left(\mathrm{mL} / \mathrm{m}^{2}\right)$ & $<0.001$ & $<0.001$ & 0.073 & 0.084 & $<0.001$ & 0.001 & 0.041 & 0.011 & 0.028 & - & - & $<0.001$ & 0.136 & 0.732 \\
\hline Indexed $V_{\text {olp }}\left(\mathrm{mL} / \mathrm{m}^{2}\right)$ & $<0.001$ & 0.003 & 0.068 & 0.012 & 0.008 & 0.007 & 0.337 & 0.008 & 0.323 & - & 0.229 & 0.026 & 0.483 & - \\
\hline Indexed $V_{\min }\left(\mathrm{mL} / \mathrm{m}^{2}\right)$ & $<0.001$ & 0.006 & 0.006 & 0.031 & 0.004 & 0.006 & 0.149 & 0.009 & 0.107 & 0.059 & 0.168 & 0.126 & 0.156 & 0.149 \\
\hline Indexed PEV $\left(\mathrm{mL} / \mathrm{m}^{2}\right)$ & 0.064 & 0.014 & 0.405 & 0.798 & 0.017 & 0.26 & 0.048 & - & 0.143 & - & - & 0.01 & - & - \\
\hline Indexed AEV $\left(\mathrm{mL} / \mathrm{m}^{2}\right)$ & 0.012 & 0.134 & 0.155 & 0.187 & 0.097 & 0.105 & 0.728 & - & - & - & - & - & - & - \\
\hline Indexed TEV $\left(\mathrm{mL} / \mathrm{m}^{2}\right)$ & $<0.001$ & 0.003 & 0.036 & 0.309 & $<0.001$ & 0.034 & 0.073 & 0.168 & 0.108 & 0.881 & - & $<0.001$ & 0.429 & - \\
\hline $\begin{array}{l}\text { LA Passive emptying } \\
\text { fraction }(\%)\end{array}$ & 0.367 & 0.537 & 0.693 & 0.314 & 0.6 & 0.727 & 0.095 & - & - & - & - & - & - & - \\
\hline $\begin{array}{l}\text { LA Active emptying fraction } \\
(\%)\end{array}$ & 0.583 & 0.67 & 0.462 & 0.741 & 0.496 & 0.668 & 0.492 & - & - & - & - & - & - & - \\
\hline $\begin{array}{l}\text { LA Total emptying fraction } \\
(\%)\end{array}$ & 0.238 & 0.863 & 0.807 & 0.2 & 0.938 & 0.253 & 0.645 & - & - & - & - & - & - & - \\
\hline
\end{tabular}

DM: Diabetes Mellitus, HT: Hypertension, HL: Hyperlipidemia, BMI: Body Mass Index, hsCRP: High Sensitive C-reactive Protein, LA: Left Atrium, PEV: Passive Emptying Volume, AEV: Active Emptying Volume, TEV: Total Emptying Volume

Table 5: Univariate and multivariate analysis for predictors of LA volumes and functions of the study population.

\section{Discussion}

The purpose of the present study was to investigate the changes in LA volumes and functions and the parameters that effect LA volumes and functions in patients with preDM based on 2D echocardiography. In this study, we demonstrated that indexed LA volumes and AEV, TEV increase significantly in preDM even which is mainly due to BMI and preDM and BMI was the only factor that had significant effect on LA functions.
Assessment of LA volumes and functions is a growing interest since changes in LA size and functions are associated with CVE such as atrial fibrillation, stroke, diastolic dysfunction and LV failure in general and diabetic population [9-17]. 2D echocardiography derived LA volume provides more accurate assessment of LA size because of the irregular geometry of LA as it often enlarges asymmetrically, resulting in variable shape that may underestimate LA size [6]. Cardiovascular imaging modalities for determination of LA functions like computed tomography (CT), cardiac magnetic resonance imaging (CMRI), and $3 \mathrm{D}$ echocardiography are still evolving. Although the main advantage 
of CMRI and CT over echocardiography is determination of all parts of LA, including LA appendage, usage of iodine and radiation during $\mathrm{CT}$, and usefulness of CMRI in patients with pacemakers limit their usage [6]. Therefore, we preferred to use 2D echocardiography which is a non-invasive, easy applicable and accessible method to evaluate LA volumes and functions.

LA volumes are evaluated by measuring $\mathrm{V}_{\text {max }}, \mathrm{V}_{\text {olp }}$ and $\mathrm{V}_{\text {min }}$ and indexed to BSA, whereas LA functions are evaluated by calculating TEV, TEF, AEV, AEF, PEV and PEF from these three volumes. TEV describes reservoir, PEV describes conduit, and AEV describes pump functions of LA. Indexed $\mathrm{V}_{\max }<29 \mathrm{ml} / \mathrm{m}^{2}$ and indexed LA diameter $<24 \mathrm{~mm} / \mathrm{m}^{2}$ for both sexes were defined as normal LA volume and LA diameter for 2D-echocardiographic evaluation [22]. Impairment of LA functions in patients with DM was demonstrated in previous studies by using $2 \mathrm{D}, 3 \mathrm{D}$ echocardiography, myocardial strain imaging, and CMRI.6 [16,17,23-25]. Moreover, Kadappu et al. reported that LA dilatation in DM was independent of associated hypertension and diastolic dysfunction which was called atrial cardiomyopathy [8]. Atrial structural and functional remodeling in DM can be explained with several mechanisms: LV diastolic dysfunction, oxidative stress, and inflammation, autonomic nervous system disbalance with enhanced sympathetic activation, increased blood pressure, and subendocardial fibrosis [6]. Recently Gudul et al reported that LA diameter; LA AEV and LA AEF were significantly higher in preDM group than control group [22]. In this study, we found that although LA volume and LV filling pressure were within normal limits LA reservoir and pump function were impaired and conduit function was similar in patients with preDM compared to controls. Moreover, we found that $\mathrm{V}_{\max }, \mathrm{V}_{\text {olp }}, \mathrm{V}_{\min }$ were associated with BMI, hsCRP, uric acid, fasting glucose, $\mathrm{HbAlc}$, and mitral $\mathrm{A}$ wave which might indicate inflammation, impaired glysemic control, LV diastolic dysfunction may alter LA volumes in preDM. We also found that BMI was the only factor that had significant effect on LA functions. On the basis of these findings, we suggest that weight control has additional importance for LA functions in patients with preDM.

\section{Limitations}

Our study had some limitations. As this was a cross-sectional study, follow-up of the patients for CVE could not be done. Therefore, we cannot comment if increased LA volumes and impaired LA functions precipitated AF or diastolic heart failure in patients with preDM. Also, as the population size was relatively small we could not evaluate IFG and IGT patients separately for LA volumes and functions and we could not analyse the effects of medications on LA volumes and functions. For this reason, long-term follow-up and large-scale prospective studies are needed to determine the clinical predictive value of LA volumes and functions in this population.

\section{Conclusion}

The results of our study showed impaired LA functions may be present in patients with preDM. BMI and preDM had significant effect on LA volumes, but BMI was the only factor that had significant effect on LA functions. We determined that impairment of LA volumes and functions might be present in patients with preDM and this finding was mainly due to preDM and BMI. 2D echocardiography can be a valuable method to assess the LA functions in preDM. Further studies with larger sample size are needed to better define the underlying mechanism and to reach a final conclusion.

\section{Acknowledgement}

The authors would like to thank Arzu Baygul from MedStats Consult'ng and Prof Sule Oktay,MD,PhD from Kappa Consulting, Traning and Limited Research Ltd. For statistical analysis and interpretation of the results.

Prof Nilgun Guvener Demirag's current affiliation is Okan University, Istanbul, and Assoc Prof Hulya Parıldar's current affiliation is Tepecık Egitim ve Arastırma Hastanesi, Izmir.

\section{References}

1. DeFronzo RA, Abdul-Ghani M (2011) Assessment and treatment of cardiovascular risk in prediabetes: Impaired glucose tolerance and impaired fasting glucose. Am J Cardiol 108: 3B-24B.

2. Coutinho M, Gerstein HC, Wang Y, Yusuf S (1999) The relationship between glucose and incident cardiovascular events. A metaregression analysis of published data from 20 studies of 95,783 individuals followed for 12.4 years. Diabetes Care 22: 233-240.

3. Galderisi M (2006) Diastolic dysfunction and diabetic cardiomyopathy: Evaluation by Doppler echocardiography. J Am Coll Cardiol 48: 1548-1551.

4. Rutter MK, Parise H, Benjamin EJ, Levy D, Larson MG, et al. (2003) Impact of glucose intolerance and insulin resistance on cardiac structure and function. Sex-related differences in Framingham Heart Study. Circulation 107: 448-454.

5. Ilercil A, Devereux RB, Roman MJ, Paranicas M, O'Grady MJ, et al. (2001) Relationship of impaired glucose tolerance to left ventricular structure and function: The strong heart study. Am Heart J 141: 992-998.

6. Tadic M, Cuspidi C (2015) The influence of type 2 diabetes on left atrial remodeling. Clin Cardiol 38: 48-55.

7. To AC, Flamm SD, Marwick TH, Klein AL (2011) Clinical utility of multimodality LA imaging: Assessment of size, function, and structure. JACC Cardiovascular Imaging 4: 788-798.

8. Kadappu KK, Boyd A, Eshoo S, Haluksa B, Yeo AET, et al. (2012) Changes in left atrial volume in diabetes mellitus: more than diastolic dysfunction. Eur Heart J 13: 1016-1023.

9. Vaziri SM, Larson MG, Benjamin EJ, Levy D (1994) Echocardiographic predictors of nonrheumatic atrial fibrillation: The Framingham Heart Study. Circulation 89: 724-730.

10. Benjamin EJ, D'Agostino RB, Belanger AJ, Wolf PA, Levy D (1995) Left atrial size and the risk of stroke and death: The Framingham Heart Study. Circulation 92: 835-841.

11. Modena MG, Muia N, Sgura FA, Molinari R, Castella A, et al. (1997) Left atrial size is the major predictor of cardiac death and overall clinical outcome in patients with dilated cardiomyopathy: A long-term follow up study. Clin Cardiol 20: 553-560.

12. Simek CL, Feldman MD, Haber HL, Wu CC, Jayaweera AR, et al. (1995) Relationship between left ventricular wall thickness and left atrial size: Comparison with other measures of diastolic function. J Am Soc Echocardiogr 8: 37-47.

13. Zoppini G, Bonapace S, Bergamini C, Rossi A, Trombetta M, et al. (2016) Evidence of left atrial remodelling and left ventricular diastolic dysfunction in type 2 diabetes mellitus with preserved systolic function. Nutr Metab Cardiovasc Dis 26: 1026-1032.

14. Armstrong AC, Gidding SS, Colengelo LA (2014) Association of early adult modifiable cardiovascular risk factors with left atrial size over 20year follow up period: The CARDIA Study. BMJ open 4: e004001.

15. TODAY Study Group (2014) Alterations in left ventricular, left atrial and right ventricular structure and function to cardiovascular risk factors in adolescent with type 2 diabetes participating in the today clinical trial. Pediatr Diabetes.

16. Atas H, Kepez A, Atas DB, Kanar BG, Dervisova R, et al. (2014) Effects of diabetes mellitus on left atrial volume anf functions in normotensive 
Citation: Gulmez O, Parildar H, Cigerli O, Demirag NG (2017) Assessment of Left Atrial Functions in Patients with Prediabetes . Gen Med (Los Angeles) 5: 296. doi:10.4172/2327-5146.1000296

Page 7 of 7

patients without sypmtomatic cardiovascular disease. J Diabetes Complications 28: 858-862.

17. Huang G, Zhang L, Xie M, Fu M, Huang J, et al. (2010) Assessment of left atrial function in diabetes mellitus by left atrial volume tracking method. J Huazhong Univ Sci Technolog Med Sci 30: 819-823.

18. American Diabetes Association (2010) Diagnosis and classification of diabetes mellitus. Diabetes Care 33: S62-69.

19. Lang RM, Badano LP, Mor-Avi V, Afilalo J, Armstrong A, et al. (2015) Recommendations for cardiac chamber quantification by echocardiography in adults: An update from the American Society of Echocardiography and European Association of Cardiovascular Imaging. J Am Soc Echocardioggr 28: 1-39.

20. Ommen SR, Nishimura RA, Appleton CP (2000) Clinical utility of Doppler echocardiography and tissue Doppler imaging in the estimation of left ventricular filling pressures: A comparative simultaneous Dopplercatheterization study. Circulation 102: 1788-1794.
21. Anwar AM, Soliman OII, Geleijnse ML, Nemes A, Vletter WB, et al. (2008) Assessment of left atrial volume and function by real-time threedimensional echocardiography. Int J Cardiol 123: 155-161.

22. Gudul NE, Karabag T, Sayın MR, Bayraktaroglu T, Aydın M (2017) Atrial conduction times and left atrial mechanical functions and their relation with diastolic function in prediabetic patients. Korean J Intern Med 32: 286-294.

23. Muranaka A, Yuda S, Tsuchihashi K, Hashimoto A, Nakata T, et al. (2009) Quantative assessment of left ventricular and left atrial functions by strain rate imaging in diabetic patients with and without hypertension. Echocardiography 26: 262-271.

24. Graca B, Ferreira MJ, Donato P (2014) Left atrial dysfunction in type 2 diabetes mellitus: Insights from cardiac MRI. Eur Radiol.

25. Mondillo S, Cameli M, Caputo ML (2011) Early detection of left atrial strain abnormalities by speckle-tracking in hypertensive and diabetic patients with normal left atrial size. J Am Soc Echocardiogr 24: 898-908. 